\title{
RADIOLOGICAL RESOLUTION IN A SEVERE COVID PATIENT: A FOLLOW-UP STUDY
}

\section{General Medicine}

Dr. K. Arun

Vishnu*

Dr. Athul.C. Angaj

Dr. Trinath Dash
Postgraduate, Dept Of Respiratory Medicine, Jawaharlal Nehru Main Hospital And Research Institute, Bhilai, Chhattisgarh, India. *Corresponding Author

Postgraduate, Dept Of Respiratory Medicine, Jawaharlal Nehru Main Hospital And Research Institute, Bhilai, Chhattisgarh, India.

Guide, Joint Director, Dept Of Respiratory Medicine, Jawaharlal Nehru Main Hospital And Research Institute, Bhilai, Chhattisgarh, India.

\section{ABSTRACT}

Pulmonary Fibrosis Is A Frequent Complication In Patients With Viral Pneumonia-induced Acute Respiratory Distress Syndrome. However, Ct Scans Have Shown That The Signs Of Pulmonary Fibrosis After Viral Pneumonia Can Partially Regress Over Time. So Now A Days, As A Part Of Covid Treatment, For Preventing Fibrosis, We Are Giving Anti Fibrotics And Steroids. But We Don't Know The Actual Sequale Of Lesions In Lung Due To Covid. Here We Would Like To Discuss About Our Case Of Severe Covid-19 Infection Who Was Managed With Anti-fibrotics, Niv, Anti-virals, Steroids And Prone Ventilation. This Particular Patient Had Ct Severity Score Of 21/25 With B/1 Ggos, Fibrotic Bands And Consolidatory Changes. A 1 Month Follow-up Ct Scan Showed A Reduction In Ct Severity Score (15/25) And Gross Resolution In Consolidatory Changes And Ggos. The Clinical Condition Showed A Significant Improvement.

\section{KEYWORDS}

\section{CASE REPORT:}

A 52 Years Old Known Hypertensive And Diabetic Patient On Regular Medication Presented With Chief Complaints Of Fever Since 4 Days

Cough With Mucoid Expectoration Since 4 Days

Sob Grade-ii Mmrc

No H/o Chestpain, Hemoptysis, Loss OfConciousness.

On Evaluation- Patient Is Conscious, Coherent And Well Oriented . Bp-130/80mmhg, Heart Rate-72/min, Respiratory Rate-26/min, Spo2\%- 90\% At Room Air Temperature- $102^{\circ} \mathrm{f}$, Auscultation Bilateral Diffuse Fine Inspiratory Crepts Present.

Patient Was Diagnosed To Be Covid-19 Positive By Rat On Day-2 Of Hospital Stay.

- Patient Was Provided Initially With A High Flow Oxygen Through Venturi Mask

- He Was Treated With I.v Broad Spectrum Antibiotics (carbapenems, Macrolides),

\begin{tabular}{|c|c|c|c|c|c|c|c|}
\hline Investigation & $05 / 09 / 20$ & $15 / 09 / 20$ & $16 / 9 / 20$ & $23 / 09 / 20$ & $1 / 10 / 20$ & $11 / 10 / 20$ & $21 / 10 / 20$ \\
\hline WBC (cumm) & 11,6000 & 13,400 & 15,900 & 14,600 & 17,100 & 11,800 & 12,000 \\
\hline $\mathrm{Hb}(\mathrm{gm} / \mathrm{dl})$ & $14.1 \mathrm{gm} / \mathrm{dl}$ & 13.8 & 13.5 & 12.9 & 13.2 & 13.4 & 13.6 \\
\hline Platelet count (cumm) & $1,35,000$ & $1,28,000$ & $1,22,000$ & $1,20,000$ & 1,00000 & $1,14,000$ & $1,25,000$ \\
\hline Sr.CREATINE (mg/dl) & 0.7 & 0.8 & 0.9 & 1.0 & 1.3 & 0.8 & 0.9 \\
\hline Bilirubin (mg/dL) & $1.5(\mathrm{D}-1.2 \& \mathrm{I}-0.3)$ & $\begin{array}{l}1.9 \\
\text { (D-1.1,I-.8 ) }\end{array}$ & $1.4(\mathrm{D}-0.7 \& \mathrm{I} 0.7)$ & $\begin{array}{l}1.3 \text { (D- } 0.8 \& \text { I- } \\
0.5)\end{array}$ & $\begin{array}{l}1.2(\mathrm{D}-0.6) \\
\& \mathrm{I}-0.6)\end{array}$ & $\begin{array}{l}1.2 \\
(\mathrm{D}-0.7, \mathrm{I}-0.5)\end{array}$ & $\begin{array}{l}1.1 \text { (D- } 0.6 \& \text { I- } \\
0.5)\end{array}$ \\
\hline LDH (U/L) & 890 & 1020 & & 1532 & 1328 & 765 & 565 \\
\hline $\mathrm{Na}+(\mathrm{mmol} / \mathrm{l})$ & 127 & & & 132 & & 134 & \\
\hline $\mathrm{K}+(\mathrm{mmol} / \mathrm{l})$ & 3.4 & & & 3.5 & & 3.9 & \\
\hline Albumin (g/dL) & 3.2 & 3.1 & & & & 4 & \\
\hline CRP ( mg/Dl) & 1.2 & & & 2.4 & & 1.2 & 0.6 \\
\hline SGOT (U/L) & 25 & 86 & & 98 & & 87 & 68 \\
\hline SGPT (U/L) & 62 & 201 & & 220 & & 190 & 160 \\
\hline $\mathrm{CA}+2$ & & & 8.1 & & & 6 & \\
\hline D-DIMER (mcg/ml) FEU & & 2 & & 1.6 & & 1.4 & 0.6 \\
\hline Sr.Ferritin (ng/ml) & & 1500 & & 1650 & & 1543 & 700 \\
\hline IL-6 (pg/ml) & & 10 & & 45 & 70 & 36 & 12 \\
\hline
\end{tabular}

HRCT CHEST:

1) CT DURING HOSPITAL STAY (26/09/2020)

S/O BILATERAL DIFFUSE GGO, SUB PLEURAL FIBROTIC

BANDS WITH THICKENED INTER LOBULAR SEPTA.

CORADS - 6 (CONFIRMED CASE OF COVID -19)
- Antiviral Drugs (remdesivir Standard Dose 200mg I.v Od Day-1 Followed By 100mg I.v Od Day 2-5),

- High Dose Iv Steroids (methylprednisolone 125mg Bid) After Inflammatory Markers Report.

- Anticoagulation (low Molecular Weight Heparin 60mg, S/c , bid).

- Antifibrotic (pirfenidone 801mg Tds)

- Supportive Medication In The Form Of Zinc, Vitamin-c, Bcomplex Etc.

- Even After The Treatment, Patient Had Severe Hypoxemia And Had To Be Put On Niv Support

- Later Was Found To Be Tolerating Niv Well And Then Was Provided Non-rebreathable Mask Support Of Which He Developed Secondary Infections, That Were Adequately Managed), With Niv And Nrm Support

- Later The Patient Was Put On Prone Ventilation- 4-5 Cycles/day With Each Cycle Lasting For 2-3 Hours

- Finally He Was Discharged With Spo2 Of $92 \%$ With Domicilary O2 Support On Demand.

His Routine Blood Investigations Revealed
- Patient Had A Relatively Long Hospital Stay (during The Course

PATIENTS RADIOLOGICAL POFILE:

CHEST X-RAY: B/L FLUFFY HOMOGENOUS SHADOWS ALL OVER THE LUNG FIELDS 

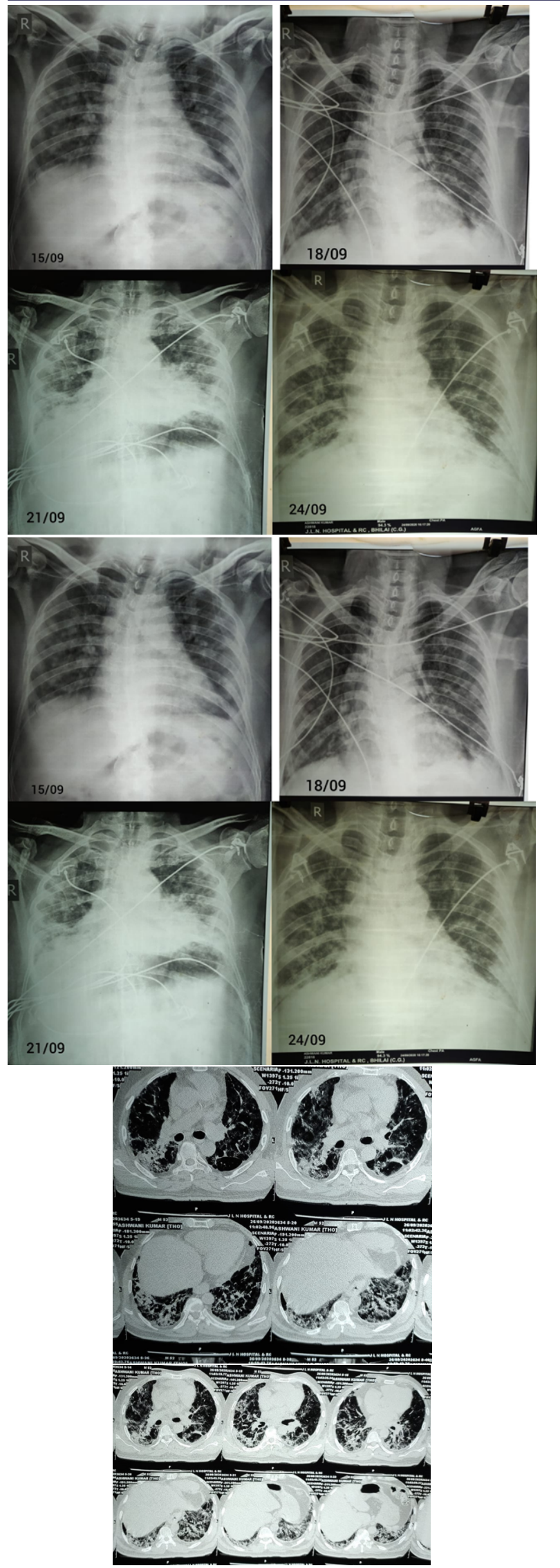

2) FOLLOW UPAFTER DISCHARGE (12/11/2020)

CT SEVERITY SCORE (15/25)

SIGNIFICANT RADIOLOGICAL IMPROVEMENT COMPARED TO PREVIOUS CT
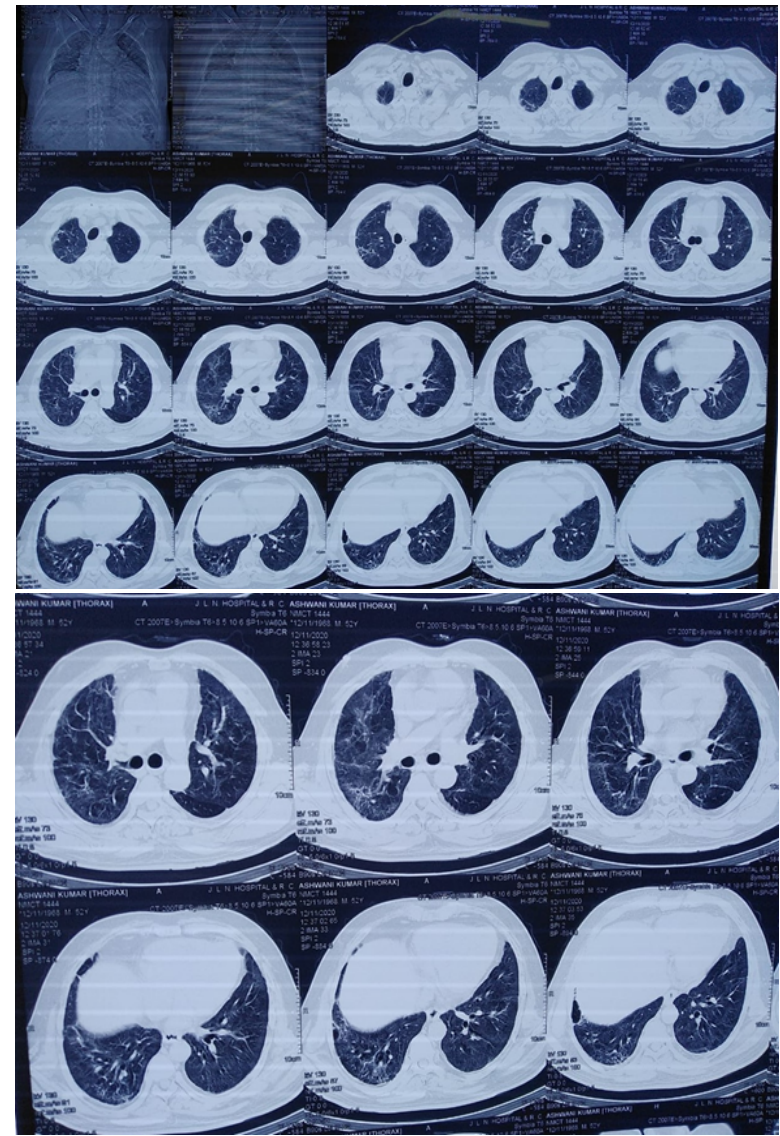

patient was initially managed by hospital covid protocol. he was responding well to treatment initially. he was found to be desaturating from day 6 of his hospital stay and was shifted to icu for critical care support. stayed in icu for a period of 10 days with niv support with escalated antibiotics and other suppportive measures.

shifted to ward and put on oral anticoagulants, started antifibrotics (pirfenidone $801 \mathrm{mg}$ tds) and put on non-rebreathable mask. he was maintaining saturation with nrm, so he was started on intermitent prone ventilation consisting of 4-5 cycles/day with each cycle lasting upto 2-3 hours. he was also advised to do incentive spirometer.

patient improved symptomatically and maintaing saturation and was hence discharged with domicilary o 2 support on demand. a 1 month follow-up ct scan showed a reduction in ct severity score $(15 / 25)$ and gross resolution in consolidatory changes and ggos. the clinical condition showed a significant improvement.

\section{DISCUSSION:}

by considering all recent data about post covid radiological sequale, it has been found that there are 3 major ways of sequale.

1) complete resolution (most common)

2) persisting radiological lesion

3) post covid fibrosis

till now we don't know the percentage of patients who may go for fibrosis lung or complete resolution. actual mechanism of resolution of lesions and fibrosis is still not completely understood. according to various studies, the fibrotic bands which are seen in covid patients is due to edematous underlying area of hyperperfusion, this may improve gradually over a period of time. the same was observed in our patient.

\section{CONCLUSION:}

- there should be proper periodical clinical and radiological follow up in each and every covid patient with significant radiological findings in ct

- patients can be followed up with hrct thorax at monthly intervals to evaluate the clinical and radiological improvement

- further studies are required regarding post covid fibrosis and also regarding the role of anti-fibrotics and steroids in preventing fibrosis 


\section{REFERENCES}

. Nasibova EM, Pashayev CN (2020) The Use of Non-Invasive Ventilation (NIV) in the Treatment of Patients with COVID-19. J Intensive \& Crit Care Vol.6 No.2:5

2. COVID-19: Respiratory support outside the intensive care unit McEnery, Tom et al. The Lancet Respiratory Medicine, Volume 8, Issue 6, 538-539

3. Use of non-invasive ventilation for patients with COVID-19: a cause for concern? Arulkumaran, Nishkantha et al. The Lancet Respiratory Medicine, Volume 8, Issue 6, e45

4. Respiratory support for patients with COVID-19 infection. Ñamendys-Silva, Silvio A. The Lancet Respiratory Medicine, Volume 8, Issue 4, e18

5. Chawla R, Nasa P. Ventilatory Management of COVID-19-related ARDS: Stick to Basics and Infection Control. Indian J Crit Care Med 2020;24(8):609-610

6. Möhlenkamp, S., Thiele, H. Ventilation of COVID-19 patients in intensive care units. Herz 45, 329-331 (2020)

7. Privitera, D., Angaroni, L., Capsoni, N. et al. Flowchart for non-invasive ventilation support in COVID-19 patients from a northern Italy Emergency Department. Intern Emerg Med 15,767-771 (2020)

8. Mahendra Damarla, Sandra Zaeh. et al. Prone Positioning of Nonintubated Patients with COVID-19." American Journal of Respiratory and Critical Care Medicine, 202(4), pp. 604-606

9. Franco C, Facciolongo N, Tonelli R, et al. Feasibility and clinical impact of out-of-ICU non-invasive respiratory support in patients with COVID-19 related pneumonia. Eur Respir J 2020; in press (https://doi.org/10.1183/13993003.02130-2020)

10. Brusasco C, Corradi F, Di Domenico A, et al. Continuous positive airway pressure in Covid-19 patients with moderate-to-severe respiratory failure. Eur Respir J 2020; in press (https://doi.org/10.1183/13993003.02524-2020)

11. Oranger M, Gonzalez-Bermejo Jésus, Dacosta-Noble P, et al. Continuous positive airway pressure to avoid intubation in SARS-CoV-2 pneumonia: a two period retrospective case-control study. Eur Respir J 2020; in press (https:// doi org/ 10.1183/ 13993003.01692-2020)

12. Chris Carter, Helen Aedy, Joy Notter.COVID-19 disease: Non-Invasive Ventilation and high frequency nasal oxygenation, Clinics in Integrated Care, Volume 1, 2020, 100006, ISSN 2666-8696, (https://doi.org/10.1016/j.intcar.2020.100006)

13. Ye T, Fan Y, Liu J, Yang C, Huang S, Xiong B. Follow-up Chest CT findings from discharged patients with severe COVID-19: an 83-day observational study.

14. Liu D, Zhang W, Pan F, Li L, Yang L, Zheng D, Wang J, Liang B. The pulmonary sequalae in discharged patients with COVID-19: a short-term observational study. Respiratory Research. 2020 Dec;21:1-7

15. Chang YC, Yu CJ, Chang SC, Galvin JR, Liu HM, Hsiao CH, Kuo PH, Chen KY, Franks TJ, Huang KM, Yang PC. Pulmonary sequelae in convalescent patients after severe acute respiratory syndrome: evaluation with thin-section CT. Radiology. 2005 acute respiratory sy

16. Chen J, Wu H, Yu Y, Tang N. Pulmonary alveolar regeneration in adult COVID-19 patients. Cell research. $2020 \mathrm{Aug} ; 30(8): 708-10$

17. Toufen Jr C. Follow-up after acute respiratory distress syndrome caused by influenza a (H1N1) virus infection. Clinics [online]. 2011, vol. 66, n. 6. ISSN. 1807;5932:933-7 